\title{
ERRATUM
}

\section{Erratum to: Overexpression, Purification, and Biochemical Characterization of the Esterase Est0796 from Lactobacillus plantarum WCFS1}

Inmaculada Navarro-González •

Álvaro Sánchez-Ferrer • Francisco García-Carmona

Published online: 9 May 2013

(c) Springer Science+Business Media New York 2013

Erratum to: Mol Biotechnol

DOI 10.1007/s12033-012-9607-7

In the original publication, the surnames and given names of the authors were reversed. The correct names appear in this erratum.

The online version of the original article can be found under doi:10.1007/s12033-012-9607-7.

I. Navarro-González ( $₫)$ · Á. Sánchez-Ferrer .

F. García-Carmona

Department of Biochemistry and Molecular Biology-A,

Faculty of Biology, University of Murcia, Campus Espinardo,

30100 Murcia, Spain

e-mail: inmaculada.navarro@um.es

F. García-Carmona

e-mail: gcarmona@um.es 